\title{
Evaluation of groundwater resources upstream of Junhe river basin in Shandong Province, China
}

\author{
Wei Zhou ${ }^{1, a}$, Jiezhong Wang ${ }^{1, b}$, Liyuan Yang ${ }^{1, ~ *}$ and Chunhua Liu ${ }^{2, c}$ \\ ${ }^{1}$ School of Resources and Environment, University of Jinan, Jinan 250022, China; \\ ${ }^{2}$ Shandong Institute of Geological Survey, Jinan 250013, China. \\ a15288878963@163.com, baking_wjz@163.com, \\ ”youngliyuan@126.com, chunhua_liu321@126.com \\ Corresponding Author: Liyuan Yang
}

Keywords: Junhe river basin, groundwater resource, water balance.

\begin{abstract}
Upstream of Junhe river basin among the mountainous region in the middle of Shandong province is deficient in groundwater resources, and the carbonate karst provides an important water supply source for this area. However, with the development of economy in the basin, much more water is consumed, resulting in the outstanding contradiction between groundwater supply and demand in this region. Hence, in order to develop and manage the groundwater effectively, an evaluation for groundwater is urgent. Based on the evaluation model of groundwater resources, the groundwater numerical simulation software GMS was employed to simulate and evaluate the water balance condition within the year of 2013. The water balance results showed that the total recharge volume in karst water system was $92.7054 \times 10^{6} \mathrm{~m}^{3} / \mathrm{a}$, and the total groundwater discharge volume was $92.5895 \times 10^{6} \mathrm{~m}^{3} / \mathrm{a}$. Overall, the equilibrium difference was $+115.9 \times 10^{3} \mathrm{~m}^{3} / \mathrm{a}$ with a positive balance.
\end{abstract}

\section{Introduction}

Water resources are closely linked with economic development and social progress. Groundwater resources constitute an important component of water resources in upstream of Junhe river basin, so reasonable exploitation and utilization of groundwater resources must be implemented to guarantees the sustainable development ${ }^{[1]}$. Junhe river basin mainly is located in Pingyi county with a monoclinic structure, which is the hilly regions in the middle-south of Shandong province. There is an abundant supply of the karst groundwater in upstream of Junhe river basin, which provides an important safeguard for the industrial and agricultural development of this region ${ }^{[2]}$. More and more groundwater is exploited in recent years. If sustainable utilization measures are not implemented, groundwater resources shortage would become a serious problem to deal with ${ }^{[3]}$.

\section{Hydrogeological characteristics}

The dominant aquifer are composed of medium-thick to thick karstic carbonate strata of Cambrian and Ordovician. Topographically, the whole stratum leaned to north-east, corresponding to the tendency of local terrain, and the southeast and northwest hilly area is the main recharge area, Junhe river basin is the lowest area of Junhe River basin. Most aquifer rocks are exposed on the surface, and some are concealed under the alluvium and diluvium. Groundwater is stored in planar-net-veined structures, and the main aquifer mediums were karst crack, karst pore space, and karst caves with unequal water content, where single well water-output is less than $1 \times 10^{3} \mathrm{~m}^{3} / \mathrm{d}$ mostly. However, karst construction of the limestone of Wuyangshan Formation is well-developed near the Difang-Yaohe-Caoche area in the north, where groundwater is discharged intensively in the monoclinic construction, and the largest single well water-output exceeds $5 \times 10^{3} \mathrm{~m}^{3} / \mathrm{d}$.

Most of the buried depth of groundwater table was less than $50 \mathrm{~m}$, with uniform and continuous water level in this region basically. Low hills in south-west was an abundant recharge area of fissure 
karst water, and the annual precipitation was $705.9 \mathrm{~mm}$ in 2013; however, the fractures differed in the horizontal and vertical directions due to the impact of the strata and construction. Therefore, groundwater output was unequal, resulting in the single well water-output varied from less than $500 \mathrm{~m}^{3} / \mathrm{d}$ to more than $5 \times 10^{3} \mathrm{~m}^{3} / \mathrm{d}$. The main discharge area was Difang-Yaohe-Guchengcun area, where the largest single well water-output was $5 \times 10^{3} \mathrm{~m}^{3} / \mathrm{d}$ or more, and some individual well water-output could reach $10 \times 10^{3} \mathrm{~m}^{3} / \mathrm{d}$.

Carbonate aquifer rocks were partly concealed under the Quaternary unconsolidated sediments of 3 24m thick near the Difang-Gucheng area. Multiple karst water leakage points and jacking recharge points were formed due to the well development of shallow karst fracture. Therefore, karst groundwater had a closely hydraulic connection with the pore water in the overlying loose rock layer $^{[4]}$. According to the analysis results of groundwater samples, the quality was better, and the salinity was $0.404 \sim 1.316 \mathrm{~g} / \mathrm{L}$, and $58 \%$ of the samples were $\mathrm{HCO}_{3} \cdot \mathrm{Ca}$ type.

\section{Groundwater dynamic change in recharge and discharge area}

The equilibrium status of groundwater can be reflected through the curves of dynamic change in groundwater level, and its fluctuation is subject to the recharge and discharge conditions as well as other multiple factors ${ }^{[5]}$. The influence factors of groundwater in different types maybe different, so the level of groundwater will have a regular fluctuation in time and space, and present different curves of groundwater dynamic change.

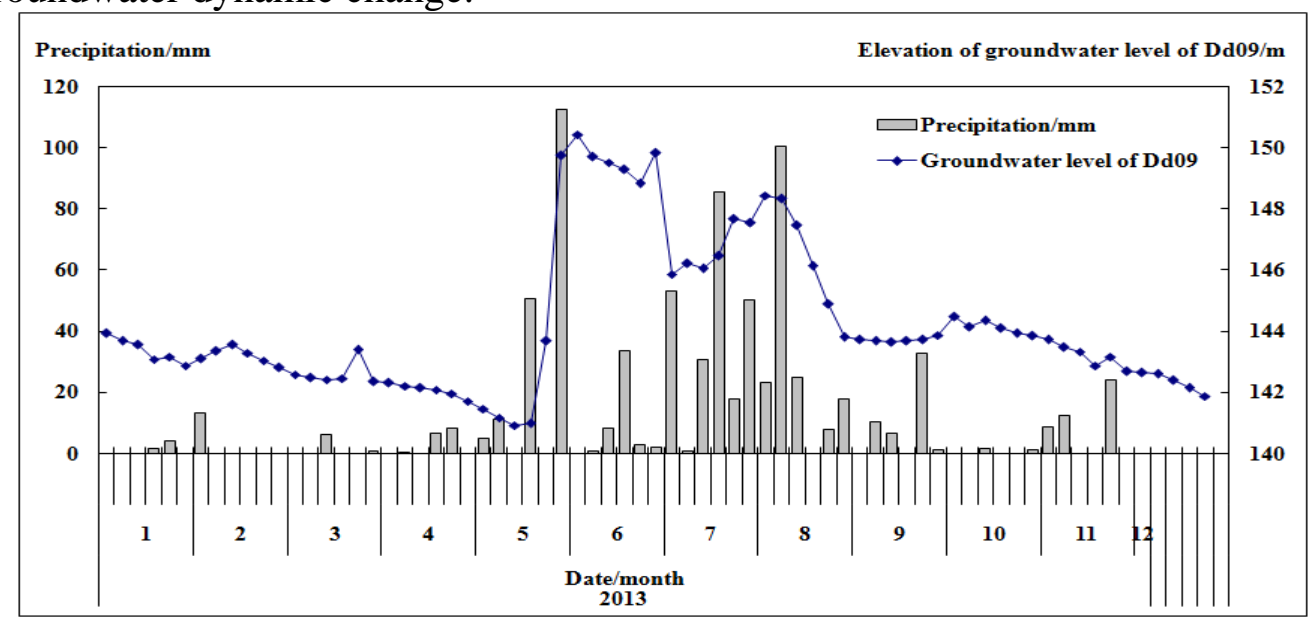

Fig. 1 Hydrograph of limestone fissure karst groundwater level in recharge area

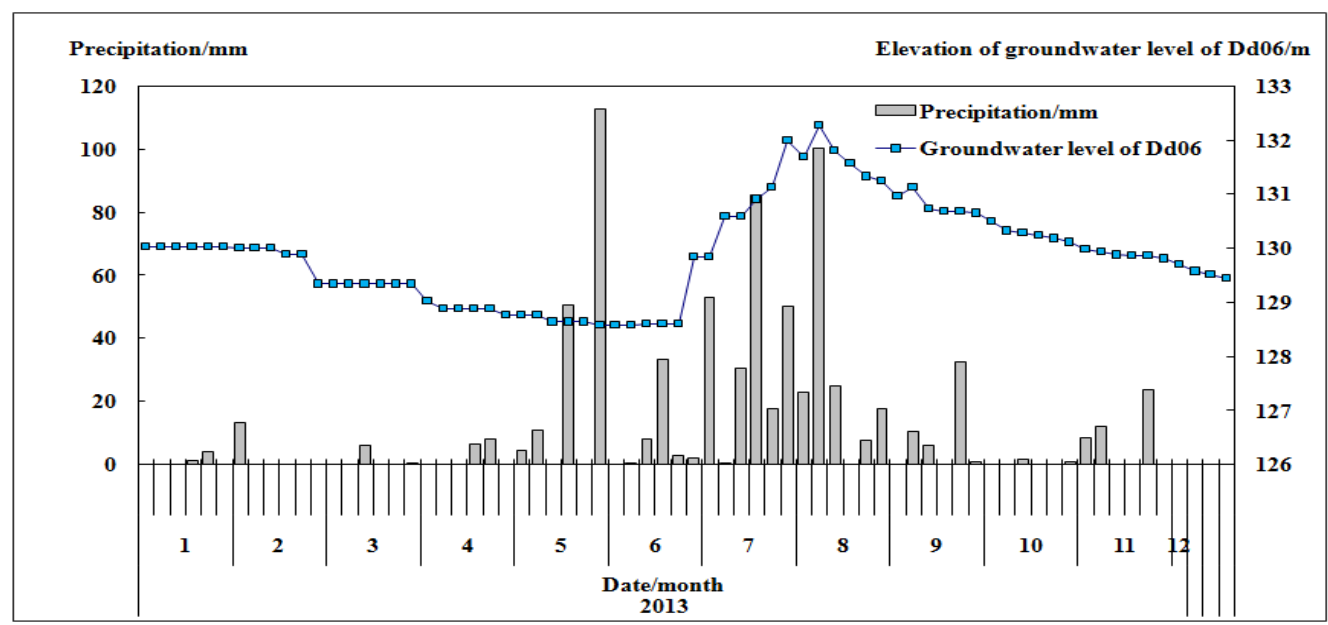

Fig. 2 Hydrograph of limestone fissure karst groundwater level in discharge area

The dynamic change of limestone karst groundwater in research area was closely related to atmospheric precipitation. Groundwater level was lowest in the mid-to-late May, while it reached the highest level in August after gaining precipitation recharge of the rainy season. As is shown in Fig 1, dynamic change within the year usually presented 'multiple peaks and valleys' and 'steep rise and 
fall', with an annual variation range of $10 \sim 20 \mathrm{~m}$, which indicated a quick response to precipitation in the recharge area. With the increase of distance from recharge area, the response of underground water level to precipitation gradually lagged in discharge area, and dynamic change within the year usually presented 'single peak and valley' and 'steep rise and slow down', with an annual variation range of 3-5m, showing that the limestone aquifer rocks in discharge area had a good function in groundwater storage, as is shown in Fig 2.

\section{Evaluation of groundwater resources}

Difang Town carbonate karst water system abundant in groundwater was chosen to be the study region of groundwater resource evaluation in Junhe river upstream, covering an area of about $261 \mathrm{~km}^{2}$. The main supply source came from precipitation infiltration, lateral runoff, river infiltration, as well as irrigation infiltration. While the main discharge items were groundwater exploitation, river channel excretion and underflow discharge. The groundwater divide between Zhutian river and Wenliang river in the south of the evaluation area was generalized into a confining boundary; the Tongshi Fault in the west border, composed of Changshan Formation aquitard, could be seen as an confining boundary; the northern boundary was aquitard of Carboniferous and Jurassic sandshale; the weathering and structure fissures of Precambrain period intrustive rock of Mengshan Fault footwall occupied the north-east part of this region, of which most could be impermeable boundary; there was a lateral runoff supply to the study region near Baoan village; however, there were two types of groundwater runoff in river and underflow in the east, because the karst water recharge Junhe river and the Quaternary period sand layer.

A model had been created in GMS (Groundwater Modeling Software) to evaluate groundwater resource of the upstream of Junhe river, and it was calibrated after relevant model datas were input, so that the accuracy of the model could meet the needs of simulation. The evaluation results showed that the total recharge volume was about $92.7054 \times 10^{6}$ million $\mathrm{m}^{3} / \mathrm{a}$ in the karst water system of the evaluation area within the year of 2013; the total discharge volume was about $92.5895 \times 10^{6} \mathrm{~m}^{3} / \mathrm{a}$. In general, the difference between recharge and discharge item was $115.9 \times 10^{3} \mathrm{~m}^{3} / \mathrm{a}$, which was a positive balance. Groundwater balance conditions of the study area are shown in table 1.

Table 1 Water balance analysis table of the study area

\begin{tabular}{lllc}
\hline & & Equilibrium quantity & Percentage \\
& & $\left(\times 10^{6} \mathrm{~m}^{3} / \mathrm{a}\right)$ & $(\%)$ \\
\hline \multirow{3}{*}{ Supply quantity } & Precipitation infiltration recharge & 57.8455 & 62.40 \\
& River leakage recharge & 22.8335 & 24.63 \\
& Irrigation leakage recharge & 1.0600 & 1.14 \\
& Lateral runoff recharge & 10.9664 & 11.83 \\
& Groundwater exploitation & 35.0027 & 37.80 \\
Discharge quantity & River excretion & 48.1647 & 52.02 \\
& Underflow discharge & 9.4221 & 10.18 \\
\hline \multirow{2}{*}{ Equilibrium difference } & & +0.1159 & \\
\hline
\end{tabular}

As can be seen from the water balance analysis table of the study area: the precipitation infiltration recharge volume was $57.8455 \times 10^{6} \mathrm{~m}^{3} / \mathrm{a}$, which accounted for the highest percentage of recharge source of all, followed by river leakage recharge volume of $22.8335 \times 10^{6} \mathrm{~m}^{3} / \mathrm{a}$. If there were any dry year, groundwater in the study area would not be effectively supplied, meanwhile the aquifer storage would be consumed by all kinds of discharge items, making it vulnerable to water shortage. What's more, it would influence the regional economic development and social stability. River channel 
excretion volume was $48.1647 \times 10^{6} \mathrm{~m}^{3} / \mathrm{a}$, which was primary in the discharge items, and groundwater exploitation also took up a large proportion. Overall, on the condition that the evaluation period was a normal flow year, groundwater level would not fluctuate obviously with a positive balance, which was consistent with the actual situation, proving that the results of model simulation conformed with the actual hydrogeological condition of the region.

\section{Summary}

In upstream of Junhe river basin, the karst groundwater was the main water resources. The response of recharge area to precipitation was more sensitive and faster than that of discharge area. According to the simulation and analysis results, the equilibrium difference of Difang Town carbonate karst water system was $115.9 \times 10^{3} \mathrm{~m}^{3} / \mathrm{a}$ with a positive balance in normal year.

\section{Acknowledgments}

This research was financially supposed by the regional hydro-geological survey Projects of Shandong Province (Shandong Survey No.(2012) 28).

\section{References}

[1]. Liu Guodong, Ding Jing. Discussion on the Evaluation Methods of Groundwater Resource in the Water Applying Field nearby a River, Advance in Water Science . Vol. 09 (1998) No. 03, p. 289-295.

[2]. Zhang Duochun, Zhang Youkuan. Application of GSFLOW to a coupled surface water and groundwater model for Shaying River Basin, Hydrogeology \& Engineering Geology . Vol. 42 (2015) No. 02, p. 1-9.

[3]. Liang Yongping, Wang Weitai. The Division and Characteristics of Karst Water Systems in Northern China , Acta Geoscientica Sinica. Vol. 31 (2010) No. 06, p. 860-868.

[4]. Wang Qingbing, Duan Xiuming, Gao Zandong, et al. Groundwater Flow Modelling in Jinan Karst spring area. Hydrogeology and Engineering Geology. (2009) No. 05, p. 53-60.

[5]. Wang Hao, Lu Chuiyu, Qin Dayong, et al. Adwances in method and application of groundwater numerical simulation. Earth Science Frontier, Vol. 17 (2010) No. 06, p. 1-12. 